\title{
Polyphenols: Key Issues Involved in Chemoprevention of Prostate Cancer
}

\author{
Sebastiano Cimino, ${ }^{1}$ Giuseppe Sortino, ${ }^{1}$ Vincenzo Favilla, ${ }^{1}$ Tommaso Castelli, ${ }^{1}$ \\ Massimo Madonia, ${ }^{2}$ Salvatore Sansalone, ${ }^{3}$ Giorgio Ivan Russo, ${ }^{1}$ and Giuseppe Morgia ${ }^{1}$ \\ ${ }^{1}$ Department of Urology, University of Catania, 95125 Catania, Italy \\ ${ }^{2}$ Department of Urology, University of Sassari, Sassari, Italy \\ ${ }^{3}$ Department of Urology, School of Medicine and Surgery, Tor Vergata University of Rome, Rome, Italy
}

Correspondence should be addressed to Sebastiano Cimino, ciminonello@hotmail.com

Received 3 February 2012; Revised 21 March 2012; Accepted 28 March 2012

Academic Editor: Tullia Maraldi

Copyright ( 92012 Sebastiano Cimino et al. This is an open access article distributed under the Creative Commons Attribution License, which permits unrestricted use, distribution, and reproduction in any medium, provided the original work is properly cited.

\begin{abstract}
Prostate cancer is is the most common solid neoplasm and it is now recognized as one of the most important medical problems facing the male population. Due to its long latency and its identifiable preneoplastic lesions, prostate cancer is an ideal target tumor for chemoprevention. Different compounds are available and certainly polyphenols represent those with efficacy against prostate cancer. This review take a look at activity and properties of major polyphenolic substances, such as epigallocatechin-3-gallate, curcumin, resveratrol and the flavonoids quercetin and genistein. Although the current studies are limited, mechanisms of action of polyphenols added with the lack of side effects show a a start for future strategies in prostate chemoprevention.
\end{abstract}

\section{Introduction}

Chemoprevention is defined as the use of specific natural (dietary) or synthetic agents to prevent, delay, or slow the carcinogenic process. Prostate cancer is an ideal target disease for chemoprevention thanks to long latency, high incidence, tumor marker availability (prostate-specific antigen, PSA), identifiable preneoplastic lesions, and because it is a very heterogeneous disease with a large subgroup of patients with nonaggressive disease [1].

Up to now the two principal targets for prostate cancer chemoprevention have been inflammation and hormonal stimulation: between all prostate cancer risk reduction studies, the only ones who were successful are PCPT (finasteride) and REDUCE (dutasteride).

Although most prostate cancers behave indolently and are undiagnosed during life, it is still the second most common cause of cancer death in men and it will become a considerable health problem in the next millennium, as the adult population is increasing $[1,2]$.
The incidence and mortality of prostate cancer shows strong variations worldwide with the highest rates in North America, Australia, Western and Northern Europe and the lowest rates in Japan and other Asian countries [1].

These wide variations have been explored and nutritional factors were found to play a role together with genetic, behavioral, occupational, and environmental ones. Since prostate cancer typically develops later in life, identifying botanical compounds to prevent or delay disease progression may have a positive effect on quality of life and reduce healthcare costs of the aging population [3].

According to the National Cancer Institute, about 400 compounds have been listed as potential chemopreventive agents and about 40 of these are currently under clinical evaluation. This paper systematically examines the data on the prostate cancer chemopreventive action of polyphenols, a class of diet constituents that showed notable efficacy in preclinical models of carcinogenesis, analyzing in particular the mechanisms of action of some polyphenolic substances, such as epigallocatechin-3-gallate, curcumin, resveratrol and the flavonoids quercetin and genistein (Table 1) [4]. 
TABLE 1: Summary of studies on polyphenols and their respective mechanisms of action.

\begin{tabular}{|c|c|c|c|c|}
\hline Compound & Type of study & $\begin{array}{l}\text { Cell culture system or } \\
\text { animal studies }\end{array}$ & Concentration used & Mechanisms of action \\
\hline $\begin{array}{l}\text { Epigallocatechin-3- } \\
\text { gallate }\end{array}$ & $\begin{array}{l}\text { In vitro } \\
{[7,8,10] \text {; in }} \\
\text { vivo }[9] \text {; in } \\
\text { humans }[12,13]\end{array}$ & $\begin{array}{l}\text { LNCaP and PC-3 [8]; } \\
\text { athymic nude mice [9]; } \\
\text { LNCaP and DU-145 [7] }\end{array}$ & $\begin{array}{l}\text { In vitro: } 10-40 \\
\text { micromol/L [8]; in vivo: } \\
\text { EGCG }(62 \%)[9] \text {; in } \\
\text { humans: } 600 \mathrm{mg} / \mathrm{d}[12] \text {; } \\
5 \text { cups/day [13] }\end{array}$ & $\begin{array}{l}\text { Activation of caspase- } 6 \\
\text { and }-9[8] \text {; reduction of } \\
\text { expression of androgen } \\
\text { receptor [9]; inhibition of } \\
\text { (MMP-2 and }-2 \text { ) and } \\
\text { VEGF [10] }\end{array}$ \\
\hline Curcumin & $\begin{array}{l}\text { In vitro } \\
{[16,19,22-25] ;} \\
\text { in humans }[28]\end{array}$ & $\begin{array}{l}\text { LNCaP }[16,20], \text { DU145 } \\
\text { and LNCaP [19]; LNCaP } \\
\text { [20]; L1210 mouse } \\
\text { leukemia cell line [22]; } \\
\text { PC-3 and DU145 [23]; } \\
\text { PC-3 [24]; DU-145 [25] }\end{array}$ & $\begin{array}{l}\text { In vitro: } 30 \mu \mathrm{mol} / \mathrm{L}[16] ; \\
10 \mu \mathrm{M}[20] ; 1-100 \mu \mathrm{M} \\
{[19] ; 0-45 \mu \mathrm{M}[22] ;} \\
1-10 \mu \mathrm{M}[23] ; 2-5 \mu \mathrm{M} \\
\text { [24]; } 10 \mathrm{mg} / \mathrm{mL}[25] ; \text { in } \\
\text { humans: } 0.4 \text { to } 3.6 \mathrm{~g} \text { [28] }\end{array}$ & $\begin{array}{l}\text { Reduction of MDM2 } \\
\text { protein and induction of } \\
\text { gene NKX3.1 [16]; } \\
\text { induction of apoptosis } \\
\text { and the activation of } \\
\text { procaspase- } 3 \text { and }-8[19] \\
\text { and caspase-9 and }-3[24] \text {; } \\
\text { reduction of MMP-2 and } \\
-9[25] \text {; decrease of PGE-2 } \\
{[28]}\end{array}$ \\
\hline Resveratrol & In vitro $[29,30]$ & $\begin{array}{l}\text { LNCaP, DU-145, PC-3 } \\
{[29] ; \text { LNCaP and }} \\
\text { DU-145 [30] }\end{array}$ & $\begin{array}{l}\text { In vitro: } 2-40 \mu \mathrm{M}[29] \\
1 \mu \mathrm{mol}[30]\end{array}$ & $\begin{array}{l}\text { Inhibition of the } \\
\text { formation of free radicals } \\
\text { [29] and induction of } \\
\text { apoptosis [30]. }\end{array}$ \\
\hline Quercetin & In vitro [31-35] & $\begin{array}{l}\mathrm{PC}-3 \text { and } \mathrm{LNCaP} \\
{[31,35] ; \mathrm{LNCaP}[32]} \\
\mathrm{PC}-3[33,34]\end{array}$ & $\begin{array}{l}\text { In vitro: } 20-40 \mu \mathrm{M}[31] \text {; } \\
100 \text { microM [32-35]; in } \\
\text { humans: } 24 \mu \mathrm{g}[36]\end{array}$ & $\begin{array}{l}\text { Activation of caspase-9 } \\
\text { and caspase-3 [31]; } \\
\text { induction of apoptosis } \\
{[32,33] \text {; downregulation }} \\
\text { of the expression of } \\
\text { MMP-2 and }-9 \text { [34]; } \\
\text { suppression of androgen } \\
\text { receptor [35] }\end{array}$ \\
\hline Genistein & $\begin{array}{l}\text { In vitro: } \\
\text { [37-39]; in vivo: } \\
{[40]}\end{array}$ & $\begin{array}{l}\text { LNCaP and PC-3 [37]; } \\
\text { LNCaP, DU-145 and } \\
\text { PC-3 [38]; PC-3 [39]. }\end{array}$ & $\begin{array}{l}\text { In vitro: } 10-20 \mu \mathrm{M} \text { [37]; } \\
20 \mu \mathrm{M}[38] ; 0-250 \mu \mathrm{M} \\
\text { [39] in humans: } 30 \mathrm{mg} \\
{[41]}\end{array}$ & $\begin{array}{l}\text { Inhibition of angiogenesis } \\
\text { and downregulation of } \\
\text { TGF- } \beta \text { and EGF }[37,42] \text {; } \\
\text { increase of the glutathione } \\
\text { peroxidase (GPX)-1 [38]; } \\
\text { decrease of metastases by } \\
96 \% \text { [39]; serum prostate } \\
\text { specific antigen (PSA) } \\
\text { decreased by } 7.8 \%[41]\end{array}$ \\
\hline
\end{tabular}

\section{Epigallocatechin-3-Gallate}

Epigallocatechin-3-gallate (EGCG) represents the major polyphenolic constituent present in green tea, the most popular beverage next to water, that has potential to be developed as a chemopreventive agent for prostate cancer (Figure 1). The tea plant (Camellia sinensis) has been cultivated in Asia for thousands of years, and Green tea has been used for centuries in China, Japan, and Thailand as a traditional medicine with a variety of applications [5].

Over the last two decades many epidemiological studies have evaluated the chemopreventive properties of green tea, suggesting that increasing intake of green tea is correlated with significant decrease in the development of prostate cancer [6].

Due to its anticarcinogenic effects, such as inhibition of growth proliferation, induction of apoptosis, induction of phase II detoxifying enzymes, and reduction of oxidative damage to DNA, various in vitro and in vivo studies have more specifically shown that consumption of green tea polyphenols is associated with decreased risk and/or slower progression of prostate cancer [5].

According to cell-culture studies, EGCG induced apoptosis and cell cycle arrest in many cancer cells without affecting normal cells. Particularly in prostate cancer cells, EGCG activates growth arrest and apoptosis primarily via p53-dependent pathway that involves the function of both p21 and Bax such that downregulation of either molecule confers a growth advantage to the cells. In androgensensitive LNCaP and androgen-insensitive PC-3 human prostate carcinoma cells, EGCG inhibited COX-2, (inducible enzymatic isoform, rapidly induced by growth factors, tumor promoters, oncogenes, and carcinogens) without affecting COX-1 expression at both the mRNA and protein levels [7].

A study published in 2007 tested the effect of epigallocatechin-3-gallate alone and in combination with specific COX-2 inhibitors on the growth and apoptosis of human prostate cancer cells both in vitro and in vivo. This study 
<smiles>O=C(O[C@H]1Cc2c(O)cc(O)cc2O[C@H]1c1cc(O)c(O)c(O)c1)c1cc(O)c(O)c(O)c1</smiles>

FIGURE 1: Epigallocatechin-3-gallate.

demonstrated a synergic action and an increased efficacy of selective COX-2 inhibitors in combination with polyphenols, from green tea, for inhibition of growth of human prostate cancer cells both in vitro and in vivo. It was observed that this effect was mainly due to increased apoptosis after increased activation of caspase-6 and caspase-9 [8].

It has been shown that ester bond-containing tea polyphenols, such as EGCG, potently and specifically inhibit the chymotrypsin-like activity of the proteasome in vitro and in vivo at the concentrations found in the serum of green tea drinkers, causing growth arrest in the $\mathrm{G}(1)$ phase of the cell cycle [7].

In a study published in 2006 the combination treatment with EGCG, green tea extract, water extract of black tea, and theaflavins was shown to reduce gene expression and protein expression of androgen receptor in the athymic nude mice implanted with androgen-sensitive human CaP CWR22R $v 1$ cells that resulted in induction of apoptosis, decrease in the levels of VEGF protein, reduction in the level of serum PSA, and a reduced tumor volume $[7,9]$.

Furthermore, this polyphenolic compound seems to inhibit tumor expression of matrix metalloproteases (MMP2 and MMP-9) and vascular endothelial growth factor (VEGF), which are overexpressed in angiogenesis, and thereby prevent the invasion and the metastatic spread of cancer [10].

In a mouse model of orthotopic androgen-sensitive human $\mathrm{PCa}$, the combination of soy phytochemical concentrate, black tea, and green tea significantly reduced tumorigenicity. This association synergistically inhibited tumor angiogenesis, final tumor weight, metastasis and significantly reduced serum concentrations of both testosterone and dihydrotestosterone in vivo [11].

A prospective, double-blind, placebo-controlled study, using a defined product of green tea in capsule form in men with HG-PIN, observed a 90\% reduction in developing Pca. This was the first study that has shown the effectiveness of green tea polyphenols for the treatment of premalignant lesions of prostate cancer [12].

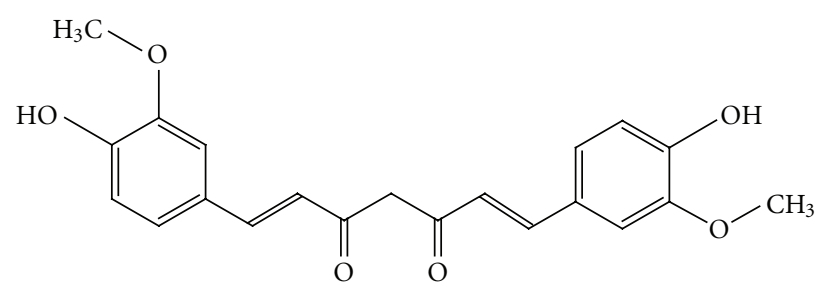

FIgURE 2: Curcumin.

In the Japan Public Health Center-based prospective study, 49,950 men aged 40 to 69 completed a questionnaire on the basis of their green tea consumption habit. Consumption was associated with a dose-dependent decrease in the risk of advanced PCa. The multivariate relative risk was 0.52 for men drinking 5 or more cups/day compared with less than 1 cup/day [13].

However, further studies are needed so that the EGCG can be safely considered as chemopreventive agents for prostate cancer.

\section{Curcumin}

Curcumin (diferuloylmethane) is a major chemical component of turmeric (Curcuma longa Linn.) and is used as a spice to give a specific flavor and yellow color to food in the Indian subcontinent (Figure 2) [14].

It has been used for centuries throughout Asia not only as a food additive but also as cosmetic and as a traditional herbal medicine to treat a variety of inflammatory conditions and chronic diseases. Over the past decade, several studies have substantiated the potential prophylactic or therapeutic value of curcumin and have unequivocally supported reports of its anticarcinogenic properties, such as its ability to influence a diverse range of molecular targets within cells. To date, no studies have reported any toxicity associated with the use of curcumin in either animals or humans [15].

The chemopreventive properties of curcumin are attributed to its effect on several targets including transcription factors, growth regulators, adhesion molecules, apoptotic genes, angiogenesis regulators, and cellular signaling molecules. It has been shown that curcumin has the ability to induce apoptosis in both androgen-dependent and androgen-independent prostate cancer cells acting through the downregulating apoptosis suppressor proteins and other crucial proteins such as the androgen receptor. In PC-3 (hormone-independent line possessing dysfunctional androgen receptors) and $\mathrm{LNCaP}$ (hormone-sensitive cells), curcumin significantly altered microfilament organization and cell motility. In PC-3, human prostate cancer cell line, curcumin reduced MDM2 protein and mRNA and enhanced the expression of the tumor suppressor p21/WAF1, a gene that encodes a potent cyclin-dependent kinase inhibitor of cyclin-CDK2 and -CDK4 complexes, inducing apoptosis and inhibiting proliferation.

Furthermore, curcumin inhibited androgen receptormediated induction of NKX3.1 expression and decreased the 
expression of androgen receptors and the binding activity to antioxidant response element directly [16].

NKX3.1, a gene located nearly on $8 \mathrm{p} 21.2$, is involved in the initiation stage of prostatic tumorigenesis. There is considerable evidence that loss of NKX3.1 expression, along with PTEN heterozygosity, a gene that codes for a lipid phosphatase and functions as a negative regulator of phosphoinositol-3-kinase (PI3K) signaling, is found at high frequency in CaP [17].

NKX3.1 gene encodes a home-box-containing transcription factor that functions as a negative regulator of epithelial cell growth in prostate tissue. Thus, cellular NKX3.1 protein levels are critical for maintenance of the prostate epithelial phenotype. Experiments conducted on LNCaP and PC-3 cells demonstrated that inflammation and in particular overproduction of TNF- $\alpha$ and IL- $\beta$ lead to rapid ubiquitination and proteasomal degradation of NKX3.1 protein through phosphorilation of serine-196 [18].

In a study, it was found that treatment of prostate cancer cells with curcumin $(1-100 \mu \mathrm{M})$ suppresses both constitutive (DU145) and inducible (LNCaP) NF- $\kappa$ B activation and potentiates TNF-induced apoptosis. Curcumin treatment (50-100 $\mu \mathrm{M})$ induced apoptosis in both cell types, which correlated with the downregulation of the expression of Bcl-2 and Bcl-xL and the activation of procaspase-3 and -8 [19].

A study also showed that curcumin blocks enhanced the effect of PSA expression by L-mimosine and dimethyloxalylglycine, prolyl hydroxylase inhibitors, which induce hypoxia condition [20].

In hormone refractory prostate cancer, it was found that curcumin, in addition to conventional treatment, may decrease prostate cancer aggressive proliferation and potentiate activity of taxane therapy increasing cytotoxicity and delaying prostate cancer cell resistance to these chemotherapeutic drugs [21-23].

In combination with radiation, curcumin $(2-5 \mu \mathrm{M})$ showed significant enhancement of radiation-induced clonogenic inhibition and apoptosis in PC-3 cells and significant activation of cytochrome $\mathrm{c}$ and caspases- 9 and -3 . These mechanisms suggest that this natural compound acts by overcoming the effects of radiation-induced prosurvival gene expression in prostate cancer [24].

Others in vitro and in vivo studies have also demonstrated the inhibitory effects exerted by treatment with only curcumin against the growth and invasiveness of DU-145 prostate cancer cells. The inhibition of tumor cell invasion was due to reductions in MMP-2 and MMP-9. Curcumin was also shown to induce a marked reduction of tumor volume. This compound may therefore have a role as a chemopreventive agent and/or adjuvant therapy in the treatment of prostate cancer, probably as a nontoxic dietary supplement [25].

Until now, few clinical data about curcumin have been performed in humans, despite the large amount of study in vitro and in animals. For these reasons, it is not yet known the pharmacokinetics properties of curcumin and its efficacious doses.

In a pilot study of a standardized oral Curcuma extract, doses up to $180 \mathrm{mg}$ of curcumin per day were administered to

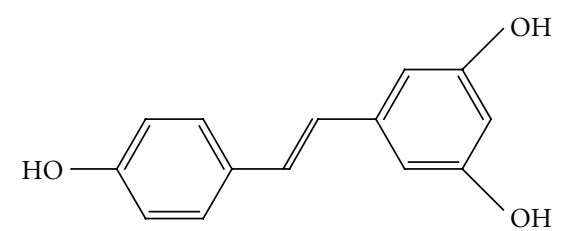

FIgURE 3: Resveratrol.

patients with advanced colorectal cancer for up to 4 months without overt toxicity or detectable systemic bioavailability [26]. A subsequent study has suggested that doses up to $8 \mathrm{~g}$ could be administered daily to patients with premalignant lesions for 3 months without overt toxicity [27].

In a phase I clinical trial of oral curcumin, fifteen patients with colorectal cancer refractory to standard chemotherapy consumed a capsule with a dose escalation between $0.4 \mathrm{~g}$ and $3.6 \mathrm{~g}$ daily for up 4 months. A daily dose of $3.6 \mathrm{~g}$ curcumin engendered $62 \%$ and $57 \%$ decreases in inducible PGE-2, suggesting a possible use of this compound for prevention outside the gastrointestinal tract [28].

\section{Resveratrol}

Resveratrol (trans-3,4',5-trihydroxystilbene, $\mathrm{C}_{14} \mathrm{H}_{12} \mathrm{O}_{3}$ ) is a plant-derived polyphenolic phytoalexin produced by the enzyme stilbene synthase in response to infection by the pathogen Botrytis cinerea and to a variety of stress conditions, such as vicissitudes in climate, exposure to ozone, sunlight and heavy metals (Figure 3). It exists in two isoforms: trans-resveratrol and cis-resveratrol where the transisomer is the more stable form. Resveratrol is present in red grapes, peanuts, some common drinks, and dietary supplements [43].

It has broad-spectrum beneficial health effects including anti-infective, antioxidant, and cardioprotective functions, but it has gained considerable attention because of its potential cancer chemopreventive properties [44]. In this regard, resveratrol represents such an ideal molecule, due to its relatively low toxicity and capacity to target multiple signaling molecules that collectively promote cancer cell survival and tumor growth. It was demonstrated that this natural compound can modulate many intracellular cancer targets, which affect cell growth, inflammation, apoptosis, angiogenesis, invasion and metastasis. It is also able to potentiate the apoptotic effects of cytokines, such as TRAIL, chemotherapeutic agents, and gamma radiation [45].

Many in vitro studies have investigated the antiproliferative or proapoptotic effects of resveratrol in human prostate cancer cells, and its mechanism of action. Resveratrol was found to inhibit the growth of LNCaP cells (hormonesensitive cells), DU-145 (androgen-independent cells), and PC-3 (hormone-independent line possessing dysfunctional androgen receptors) in a concentration-dependent manner. It has also been shown to exert a strong inhibitory effect on the formation of free radicals in human macrophages, reducing oxidative stress within premalignant cells, and to 
<smiles>O=c1c(O)c(-c2ccc(O)c(O)c2)oc2cc(O)cc(O)c12</smiles>

Figure 4: Quercetin.

decrease the production of NO in PC-3 and DU-145 cells, reducing growth and spread of prostate cancer [29].

About its proapoptotic effects, it has been shown to induce apoptosis in LNCaP and DU145 prostate cancer cell lines through different PKC-mediated and MAPKdependent pathways [30].

Furthermore, resveratrol-mediated apoptosis has been associated with p53 activation and also occurs via the death receptor Fas/CD95/APO-1 in various human cancer cells [45].

It is also possible that resveratrol exerts its chemopreventive action in part by modulating the expression or function of androgen receptor [29].

Another interesting chemopreventive mechanism related with this compound is represented by sensitization effect. Research from in vitro and in vivo studies indicate that resveratrol can overcome chemoresistance in tumor cells by modulating apoptotic pathways, downregulating drug transporters, downmodulating proteins involved in tumor cell proliferation, and inhibiting NF- $\kappa$ B and STAT-3 pathway [44].

Goldberg et al. reported that, after an oral dose of resveratrol $(25 \mathrm{mg} / 70 \mathrm{~kg})$, catechin $(25 \mathrm{mg} / 70 \mathrm{~kg})$, and quercetin ( $10 \mathrm{mg} / 70 \mathrm{~kg}$ ) to healthy human subjects, these compounds appeared in serum and urine predominantly as glucuronide and sulfate conjugates and free polyphenols accounted for $1.7-1.9 \%$ (resveratrol), 1.1 to $6.5 \%$ (catechin), and 17.2 to $26.9 \%$ (quercetin) of the peak serum concentrations and more than $80 \%$ is absorbed. The absorption of transresveratrol was the most efficient as judged by peak serum concentration (16-17\% of dose consumed) [46].

\section{Quercetin}

Quercetin is the main representative of the flavonol class and a polyphenolic antioxidant found in a variety of fruits and vegetables, highly concentrated in onions, broccoli, apples, grapes (red wine), and in soybeans (Figure 4).

This flavonoid, besides having antioxidant and antiinflammatory activities, has been shown to possess potent antiproliferative effects against various malignant cells, although its molecular mechanism involved in chemoprevention of prostate cancer remains unclear in many respects [47]. Quercetin treatment has been associated with selective antiproliferative effects and induction of cell death, predominantly through an apoptotic mechanism, in cancer cell lines. This compound seems to be able to induce apoptosis through multiple mechanisms: causing arrest in the $G_{1}$ phase of the cell cycle or through interaction with cell cycle-regulated proteins, like cyclin D1 and CDK4; releasing cytochrome c and activating caspase- 9 and caspase-3; through inhibition of $\mathrm{PI} 3 \mathrm{~K}$, an enzyme involved in the pivotal cell survival pathway, synergizing the effect of ECGC [31].

Epidemiological studies and preliminary data have shown that quercetin inhibits the onset/growth of prostate cancer. It was noted that there is a $27 \%$ risk reduction for prostate cancer for those who consume at least $24 \mu \mathrm{g}$ of quercetin a day [36].

In human prostate carcinoma $\mathrm{LNCaP}$ cells, quercetin inhibited the PI3K/Akt pathway, suppressed the phosphorylation of Bad, proapoptotic $\mathrm{Bcl}-2$ family member, and subsequently altered the interaction between $\mathrm{Bcl}-\mathrm{xL}$ and $\mathrm{Bax}$, leading to cytochrome $\mathrm{c}$ release, activation of caspases and consequently apoptotic death [32].

It was also found that quercetin inhibits the proliferation of PC-3 cells causing a significant decrease in Cdc2/Cdk-1 and cyclin $\mathrm{B} 1$ protein expressions and increasing hypophosphorylated level of $\mathrm{pRb}$ and this may be attributed to decreased expression of growth responsive genes and subsequent growth inhibition of PC-3 cells [33].

Another important chemopreventive activity of quercetin might be to reduce the risk of prostate cancer metastasis. Tumor invasion and metastasis represent a multistep process that depends on the activity of many proteins. Proteolytic degradation of the extracellular matrix components is a central event of this process, primarily due to the action of matrix metalloproteinases.

A study showed that this natural compound inhibits the expression of MMP 2 and 9 in prostate cancer cells (PC-3). As it has been detected that MMP-2 and 9 expressions were regulated by MAP kinase signaling pathways and quercetin is an inhibitor of several kinases including MAP kinases and tyrosine kinases, it is reasonable to speculate that quercetin might have downregulated the expression of MMP-2 and -9 through inhibition of protein kinases [34].

In addition, quercetin appears to have the ability to suppress the function of androgen receptor, pivotal molecule in normal development of the prostate and in the development and progression of prostate cancer. Quercetin-mediated inhibition of the androgen receptor transcription activity in prostate cancer cells may be caused, at least in part, by the formation of a protein complex containing c-Jun, Sp1, and androgen receptor, but further investigation will be necessary to examine whether other factors are also involved in this protein complex [35].

\section{Genistein}

Genistein (4',5,7-trihydroxyisoflavone), the predominant isoflavone in human nutrition, is derived mainly from soybeans but also from other legumes, including peas, lentils, or beans (Figure 5) [38]. 


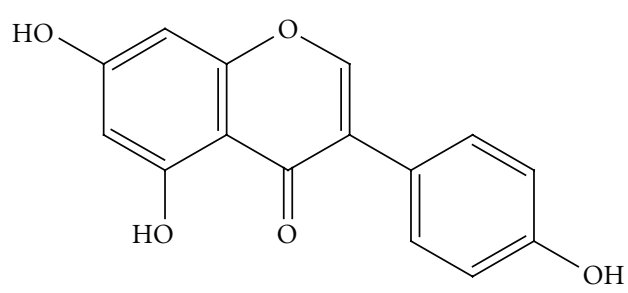

FIGURE 5: Genistein.

Genistein has many important health benefits, such as lowering the incidence of cardiovascular diseases, prevention of osteoporosis, attenuation of postmenopausal problems, reduction of body mass and fat tissue. It also has chemopreventive properties, and in particular genistein has been shown to inhibit growth of both androgen-dependent and -independent prostate cancer cells in vitro. Several mechanisms have been proposed for genistein anticarcinogenic activity: inhibition of protein-tyrosine kinase, with the result of alleviating the growth of cancer cells by inhibiting PTK-mediated signaling mechanisms; inhibition of topoisomerases I and II and protein histidine kinase with antiproliferative or proapoptotic effects; antioxidant effects, through inhibition of the expression of stress response related genes; inhibition of NF- $\kappa \mathrm{B}$ and Akt signaling pathways, both of which are important for cell survival; the inhibition of angiogenesis; the downregulation of transforming growth factor-beta (TGF- $\beta$ ), and the inhibition of epidermal growth factor (EGF) [37, 42].

In vitro studies have also demonstrated that this natural compound downregulates the androgen receptor of PCa cells via the estrogen receptor $\beta$, resulting in a modified response to hormonal stimuli, inhibits several steroid-metabolizing enzymes such as $5-\alpha$-reductase or aromatase creating a more favorable hormonal milieu and a protective effect against prostate cancer, blocks the cell cycle progression at $\mathrm{G}_{1}$, and inhibits PSA expression [38].

With regard to its antioxidant activity, a study examined the effect of genistein on human prostate cancer (LNCaP and PC-3) cells. To obtain the gene expression profile of genistein in LNCaP cells, it was performed cDNA microarray analysis. This survey has shown that while the expression of many genes, including apoptosis inhibitor (survivin), DNA topoisomerase II, cell division cycle 6 (CDC6), and mitogenactivated protein kinase 6 (MAPK 6), was downregulated, the glutathione peroxidase (GPx)-1 gene expression level was upregulated with a subsequent increase of GPx enzyme activities.

The tumor initiation and progression are often attributed to oxidative stress and the generation of ROS, which exceed cell ability of metabolize and detoxify them.

In addition to causing genetic changes, ROS may lead to epigenetic alterations that affect the genome and play a key role in the development of human carcinogenesis [40].

More specifically, ROS production is associated with alterations in DNA methylation patterns.
Furthermore, ROS-induced oxidative stress can contribute to gene silencing by mechanisms that involve aberrant hypermethylation of tumor suppressor gene promoter regions and thus lead towards progression to a malignant phenotype [48].

Oxygen radicals may cause damage to DNA and chromosomes, induce epigenetic alterations, interact with oncogenes or tumor suppressor genes, and impart changes in immunological mechanisms, like mutation of nuclear encoded genes such as TP53, promotes carcinogenesis $[49,50]$.

ROS are further determinant for the activation of inflammatory pathways that play a key role in cancer progression. Inflammation in cancer involves a close interplay between tumor-associated immune cells and the tumor cells themselves. Activation of NF- $\kappa \mathrm{B}$ and AP- 1 in immune cells, induced by ROS, determines production of inflammatory cytokines such as TNF $\alpha$ and IL- 6 that have been demonstrated to be important in tumor progression [51].

Since ROS are considered key participants in the progression cancer, the antioxidant effect of genistein might prevent tumor invasion or metastasis in prostate cancer cells inhibiting production of matrix metalloproteinase, cell motility and degradation of the basement membrane. [52].

The antimetastatic potential of genistein was evaluated by a study through the development of an animal model, a murine model of human PCa metastasis. It has been demonstrated that genistein inhibits initial steps in the metastatic cascade, namely, cell detachment and cell invasion and for the first time induces flattening of cell nuclei in vivo, a measure of increased cell attachment. Furthermore, genistein, through inhibition of phosphorylation, has been shown to inhibit activation of p38 MAPK and FAK (promotility proteins) in vivo, blocking cell motility. Genistein decreased metastases by $96 \%$, induced nuclear morphometric changes in PC3-M cells indicative of increased adhesion (i.e., decreased detachment) but did not alter tumor growth. This study showed for the first time that dietary concentrations of genistein can inhibit prostate cancer cell metastasis, but more specific analysis on the genistein effects upon human prostate cells needed [39].

Another interesting study has investigated the potential additive and synergistic effects of genistein and resveratrol for suppressing prostate cancer in the Simian Virus-40 Tantigen (SV-40 Tag) targeted probasin promoter rat model, a transgenic model of spontaneously developing prostate cancer. It has been shown that high dose genistein and resveratrol treatments, reducing cell proliferation and increasing apoptosis mainly through the modulation of sex steroid receptor and growth factor signaling, suppress the most severe grade of prostate cancer in these transgenic animals [53].

In a randomized, placebo-controlled, double-blind phase II clinical trial, fifty-four study subjects were recruited and randomized to treatment with genistein $30 \mathrm{mg}(n=23)$ or placebo $(n=24)$ for 3 to 6 wk prior to prostatectomy. Serum prostate specific antigen (PSA) decreased by $7.8 \%$ in the genistein arm and increased by $4.4 \%$ in the placebo arm, without adverse events and with beneficial effect on blood cholesterol [41]. 


\section{Conclusions}

Since prostate cancer is one of the most important medical problems afflicting male population, chemoprevention strategies represent a promising approach to reduce the incidence and mortality of this. Unfortunately, scientific evidences about polyphenols should be still demonstrated and well-conducted clinical studies are needed to clarify the efficacy of these molecules on prevention of PCa.

It should be better regulated the wide use of different dietary agents; in fact, being extractive products and not synthetic products, they may elicit a great variability of therapeutic results.

Among all mechanisms of action, these compounds have shown antioxidant effects by similar molecular pathways, indicating a possible use of the associations of these polyphenols, but few results have been developed.

Although a large amount of studies in vitro have been conducted until now, few clinical trials, using precise concentrations of these compounds, have been performed. For these reasons, we encourage to conduct further investigations and more extensive studies to obtain conclusive evidences. Despite all, different biomolecular mechanisms of action are promising, suggesting a real application in prostate cancer prevention. Inhibition of angiogenesis, induction of apoptosis, and reduction of tumor volume represent a start for future strategies in prostate chemoprevention, and understanding the underlying mechanisms of action, especially on humans, may change the natural history of this tumor.

\section{References}

[1] H. van Poppel and B. Tombal, "Chemoprevention of prostate cancerwith nutrients and supplements," Cancer Management and Research, vol. 3, no. 1, pp. 91-100, 2011.

[2] R. S. Rittmaster, "Chemoprevention of prostate cancer," Acta Oncologica, vol. 50, supplement 1, pp. 127-136, 2011.

[3] A. Ślusarz, N. S. Shenouda, M. S. Sakla et al., "Common botanical compounds inhibit the hedgehog signaling pathway in prostate cancer," Cancer Research, vol. 70, no. 8, pp. 33823390, 2010.

[4] S. C. Thomasset, D. P. Berry, G. Garcea, T. Marczylo, W. P. Steward, and A. J. Gescher, "Dietary polyphenolic phytochemicals_-promising cancer chemopreventive agents in humans? A review of their clinical properties," International Journal of Cancer, vol. 120, no. 3, pp. 451-458, 2007.

[5] M. Pandey and S. Gupta, "Green tea and prostate cancer: from bench to clinic," Frontiers in Bioscience, vol. 1, pp. 13-25, 2009.

[6] J. J. Johnson, H. H. Bailey, and H. Mukhtar, "Green tea polyphenols for prostate cancer chemoprevention: a translational perspective," Phytomedicine, vol. 17, no. 1, pp. 3-13, 2010.

[7] N. Khan, V. M. Adhami, and H. Mukhtar, "Review: green tea polyphenols in chemoprevention of prostate cancer: preclinical and clinical studies," Nutrition and Cancer, vol. 61, no. 6, pp. 836-841, 2009.

[8] V. M. Adhami, A. Malik, N. Zaman et al., "Combined inhibitory effects of green tea polyphenols and selective cyclooxygenase- 2 inhibitors on the growth of human prostate cancer cells both in vitro and in vivo," Clinical Cancer Research, vol. 13, no. 5, pp. 1611-1619, 2007.
[9] I. A. Siddiqui, N. Zaman, M. H. Aziz et al., "Inhibition of CWR22R $v 1$ tumor growth and PSA secretion in athymic nude mice by green and black teas," Carcinogenesis, vol. 27, no. 4, pp. 833-839, 2006.

[10] V. M. Adhami, N. Ahmad, and H. Mukhtar, "Molecular targets for green tea in prostate cancer prevention," Journal of Nutrition, vol. 133, no. 7, pp. 2417S-2424S, 2003.

[11] J. R. Zhou, L. Yu, Y. Zhong, and G. L. Blackburn, "Soy phytochemicals and tea bioactive components synergistically inhibit androgen-sensitive human prostate tumors in mice," Journal of Nutrition, vol. 133, no. 2, pp. 516-521, 2003.

[12] S. Bettuzzi, M. Brausi, F. Rizzi, G. Castagnetti, G. Peracchia, and A. Corti, "Chemoprevention of human prostate cancer by oral administration of green tea catechins in volunteers with high-grade prostate intraepithelial neoplasia: a preliminary report from a one-year proof-of-principle study," Cancer Research, vol. 66, no. 2, pp. 1234-1240, 2006.

[13] N. Kurahashi, S. Sasazuki, M. Iwasaki, and M. Inoue, "Green tea consumption and prostate cancer risk in Japanese men: a prospective study," American Journal of Epidemiology, vol. 167, no. 1, pp. 71-77, 2008.

[14] N. Khan, V. M. Adhami, and H. Mukhtar, "Apoptosis by dietary agents for prevention and treatment of prostate cancer," Endocrine-Related Cancer, vol. 17, no. 1, pp. R39-R52, 2010.

[15] A. Goel and B. B. Aggarwal, "Curcumin, the golden spice from Indian saffron, is a chemosensitizer and radiosensitizer for tumors and chemoprotector and radioprotector for normal organs," Nutrition and Cancer, vol. 62, no. 7, pp. 919-930, 2010.

[16] N. Khan, F. Afaq, and H. Mukhtar, "Cancer chemoprevention through dietary antioxidants: progress and promise," Antioxidants and Redox Signaling, vol. 10, no. 3, pp. 475-510, 2008.

[17] D. N. Syed, N. Khan, F. Afaq, and H. Mukhtar, "Chemoprevention of prostate cancer through dietary agents: progress and promise," Cancer Epidemiology Biomarkers and Prevention, vol. 16, no. 11, pp. 2193-2203, 2007.

[18] M. C. Markowski, C. Bowen, and E. P. Gelmann, "Inflammatory cytokines induce phosphorylation and ubiquitination of prostate suppressor protein NKX3.1," Cancer Research, vol. 68, no. 17, pp. 6896-6901, 2008.

[19] A. Mukhopadhyay, C. Bueso-Ramos, D. Chatterjee, P. Pantazis, and B. B. Aggarwal, "Curcumin downregulates cell survival mechanisms in human prostate cancer cell lines," Oncogene, vol. 20, no. 52, pp. 7597-7609, 2001.

[20] L. C. Chung, K. H. Tsui, T. H. Feng, S. L. Lee, P. L. Chang, and H. H. Juang, "Curcumin provides potential protection against the activation of hypoxia and prolyl 4-hydroxylase inhibitors on prostate-specific antigen expression in human prostate carcinoma cells," Molecular Nutrition \& Food Research, vol. 55, no. 11, pp. 1666-1676, 2011.

[21] A. Cabrespine-Faugeras, M. Bayet-Robert, J. O. Bay, P. Chollet, and C. Barthomeuf, "Possible benefits of curcumin regimen in combination with taxane chemotherapy for hormonerefractory prostate cancer treatment," Nutrition and Cancer, vol. 62, no. 2, pp. 148-153, 2010.

[22] B. H. Choi, C. G. Kim, Y. Lim, S. Y Shin, and Y. H. Lee, "Curcumin down-regulates the multidrug-resistance mdrlb gene by inhibiting the PI3K/Akt/NF kappa B pathway," Cancer Letters, vol. 259, no. 1, pp. 111-118, 2008.

[23] T. C. Hour, J. Chen, C. Y. Huang, J. Y. Guan, S. H. Lu, and Y. $\mathrm{S}$. $\mathrm{Pu}$, "Curcumin enhances cytotoxicity of chemotherapeutic agents in prostate cancer cells by inducing p21WAF1/CIP1 
and C/EBP $\beta$ expressions and suppressing NF- $\kappa \mathrm{B}$ activation," Prostate, vol. 51, no. 3, pp. 211-218, 2002.

[24] D. Chendil, R. S. Ranga, D. Meigooni, S. Sathishkumar, and M. M. Ahmed, "Curcumin confers radiosensitizing effect in prostate cancer cell line PC-3," Oncogene, vol. 23, no. 8, pp. 1599-1607, 2004.

[25] J. H. Hong, K. S. Ahn, E. Bae, S. S. Jeon, and H. Y. Choi, "The effects of curcumin on the invasiveness of prostate cancer in vitro and in vivo," Prostate Cancer and Prostatic Diseases, vol. 9, no. 2, pp. 147-152, 2006.

[26] R. A. Sharma, H. R. McLelland, K. A. Hill et al., "Pharmacodynamic and pharmacokinetic study of oral Curcuma extract in patients with colorectal cancer," Clinical Cancer Research, vol. 7, no. 7, pp. 1894-1900, 2001.

[27] A. L. Chen, C. H. Hsu, J. K. Lin et al., "Phase I clinical trial of curcumin, a chemopreventive agent, in patients with high-risk or pre-malignant lesions," Anticancer Research, vol. 21, no. 4, pp. 2895-2900, 2001.

[28] R. A. Sharma, S. A. Euden, S. L. Platton et al., "Phase I clinical trial of oral curcumin: biomarkers of systemic activity and compliance," Clinical Cancer Research, vol. 10, no. 20, pp. 6847-6854, 2004.

[29] H. L. Ratan, W. P. Steward, A. J. Gescher, and J. K. Mellon, "Resveratrol-a prostate cancer chemopreventive agent?" Urologic Oncology, vol. 7, no. 6, pp. 223-227, 2002.

[30] A. Shih, S. Zhang, H. J. Cao et al., "Inhibitory effect of epidermal growth factor on resveratrol-induced apoptosis in prostate cancer cells is mediated by protien kinase C- $\alpha$," Molecular Cancer Therapeutics, vol. 3, no. 11, pp. 1355-1363, 2004.

[31] S. N. Tang, C. Singh, D. Nall, D. Meeker, S. Shankar, and R. K. Srivastava, "The dietary bioflavonoid quercetin synergizes with epigallocathechin gallate (EGCG) to inhibit prostate cancer stem cell characteristics, invasion, migration and epithelial-mesenchymal transition," Journal of Molecular Signaling, vol. 5, article 14, 2010.

[32] D. H. Lee, M. Szczepanski, and Y. J. Lee, "Role of Bax in quercetin-induced apoptosis in human prostate cancer cells," Biochemical Pharmacology, vol. 75, no. 12, pp. 2345-2355, 2008.

[33] M. R. Vijayababu, P. Kanagaraj, A. Arunkumar, R. Ilangovan, M. M. Aruldhas, and J. Arunakaran, "Quercetin-induced growth inhibition and cell death in prostatic carcinoma cells (PC-3) are associated with increase in p21 and hypophosphorylated retinoblastoma proteins expression," Journal of Cancer Research and Clinical Oncology, vol. 131, no. 11, pp. 765-771, 2005.

[34] M. R. Vijayababu, A. Arunkumar, P. Kanagaraj, P. Venkataraman, G. Krishnamoorthy, and J. Arunakaran, "Quercetin downregulates matrix metalloproteinases 2 and 9 proteins expression in prostate cancer cells (PC-3)," Molecular and Cellular Biochemistry, vol. 287, no. 1-2, pp. 109-116, 2006.

[35] H. Yuan, C. Y. F. Young, Y. Tian, Z. Liu, M. Zhang, and H. Lou, "Suppression of the androgen receptor function by quercetin through protein-protein interactions of Sp1, c-Jun, and the androgen receptor in human prostate cancer cells," Molecular and Cellular Biochemistry, vol. 339, no. 1-2, pp. 253-262, 2010.

[36] S. E. McCann, C. B. Ambrosone, K. B. Moysich et al., "Intakes of selected nutrients, foods, and phytochemicals and prostate cancer risk in Western New York," Nutrition and Cancer, vol. 53, no. 1, pp. 33-41, 2005.

[37] R. Zhao, N. Xiang, F. E. Domann, and W. Zhong, "Effects of selenite and genistein on G2/M cell cycle arrest and apoptosis in human prostate cancer cells," Nutrition and Cancer, vol. 61, no. 3, pp. 397-407, 2009.

[38] F. G. E. Perabo, E. C. Von Löw, J. Ellinger, A. von Rücker, S. C. Müller, and P. J. Bastian, "Soy isoflavone genistein in prevention and treatment of prostate cancer," Prostate Cancer and Prostatic Diseases, vol. 11, no. 1, pp. 6-12, 2008.

[39] M. Lakshman, L. Xu, V. Ananthanarayanan et al., "Dietary genistein inhibits metastasis of human prostate cancer in mice," Cancer Research, vol. 68, no. 6, pp. 2024-2032, 2008.

[40] A. C. E. Campos, F. Molognoni, F. H. M. Melo et al., "Oxidative stress modulates DNA methylation during melanocyte anchorage blockade associated with malignant transformation," Neoplasia, vol. 9, no. 12, pp. 1111-1121, 2007.

[41] B. Lazarevic, G. Boezelijn, and L. M. Diep, "Efficacy and safety of short-term genistein intervention in patients with localized prostate cancer prior to radical prostatectomy: a randomized, placebo-controlled, double-blind Phase 2 clinical trial," Nutrition and Cancer, vol. 63, no. 6, pp. 889-898, 2011.

[42] S. Banerjee, Y. Li, Z. Wang, and F. H. Sarkar, "Multi-targeted therapy of cancer by genistein," Cancer Letters, vol. 269, no. 2, pp. 226-242, 2008.

[43] M. Athar, J. H. Back, X. Tang et al., "Resveratrol: a review of preclinical studies for human cancer prevention," Toxicology and Applied Pharmacology, vol. 224, no. 3, pp. 274-283, 2007.

[44] S. C. Gupta, R. Kannappan, S. Reuter, J. H. Kim, and B. B. Aggarwal, "Chemosensitization of tumors by resveratrol," Annals of the New York Academy of Sciences, vol. 1215, no. 1, pp. 150-160, 2011.

[45] M. Athar, J. H. Back, L. Kopelovich, D. R. Bickers, and A. L. Kim, "Multiple molecular targets of resveratrol: anticarcinogenic mechanisms," Archives of Biochemistry and Biophysics, vol. 486, no. 2, pp. 95-102, 2009.

[46] D. M. Goldberg, J. Yan, and G. J. Soleas, "Absorption of three wine-related polyphenols in three different matrices by healthy subjects," Clinical Biochemistry, vol. 36, no. 1, pp. 7987, 2003.

[47] M. R. Vijayababu, P. Kanagaraj, A. Arunkumar, R. Ilangovan, A. Dharmarajan, and J. Arunakaran, "Quercetin induces p53independent apoptosis in human prostate cancer cells by modulating Bcl-2-related proteins: a possible mediation by IGFBP-3," Oncology Research, vol. 16, no. 2, pp. 67-74, 2006.

[48] D. Ziech, R. Franco, A. Pappa, and M. I. Panayiotidis, "Reactive Oxygen Species (ROS) - induced genetic and epigenetic alterations in human carcinogenesis," Mutation Research, vol. 711, no. 1-2, pp. 167-173, 2011.

[49] K. V. Donkena, C. Y. Young, and D. J. Tindall, "Oxidative stress and DNA methylation in prostate cancer," Obstetrics and Gynecology International, vol. 2010, Article ID 302051, 14 pages, 2010.

[50] F. Colotta, P. Allavena, A. Sica, C. Garlanda, and A. Mantovani, "Cancer-related inflammation, the seventh hallmark of cancer: links to genetic instability," Carcinogenesis, vol. 30, no. 7, pp. 1073-1081, 2009.

[51] K. E. Wellen and C. B. Thompson, "Cellular metabolic stress: considering how cells respond to nutrient excess," Molecular Cell, vol. 40, no. 2, pp. 323-332, 2010.

[52] K. Suzuki, H. Koike, H. Matsui et al., "Genistein, a soy isoflavone, induces glutathione peroxidase in the human prostate cancer cell lines LNCaP and PC-3," International Journal of Cancer, vol. 99, no. 6, pp. 846-852, 2002.

[53] C. E. Harper, L. M. Cook, B. B. Patel et al., "Genistein and resveratrol, alone and in combination, suppress prostate cancer in SV-40 tag rats," Prostate, vol. 69, no. 15, pp. 16681682, 2009. 


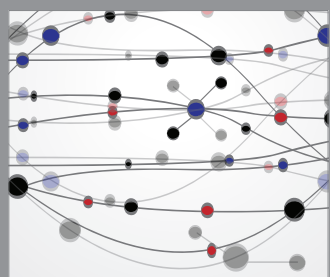

The Scientific World Journal
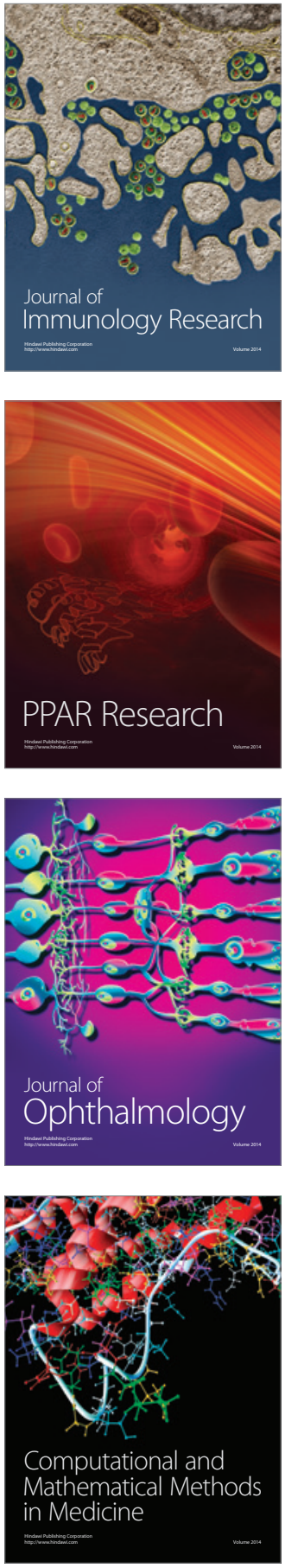

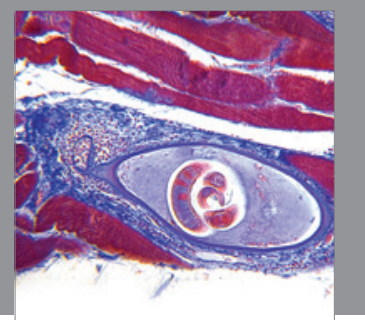

Gastroenterology

Research and Practice
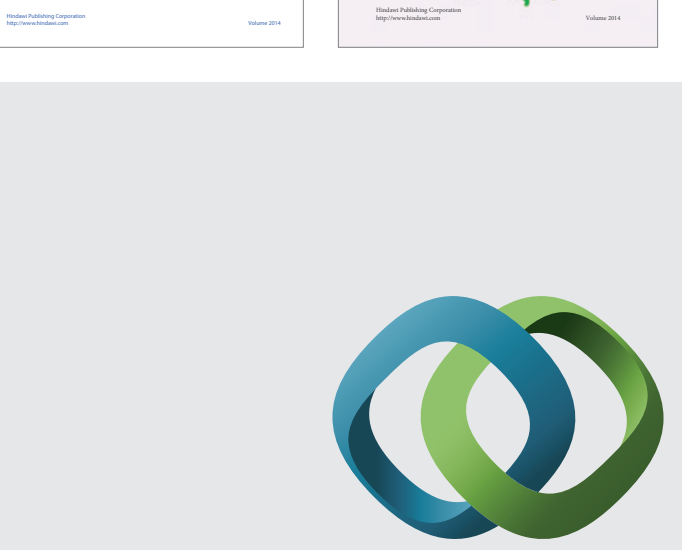

\section{Hindawi}

Submit your manuscripts at

http://www.hindawi.com
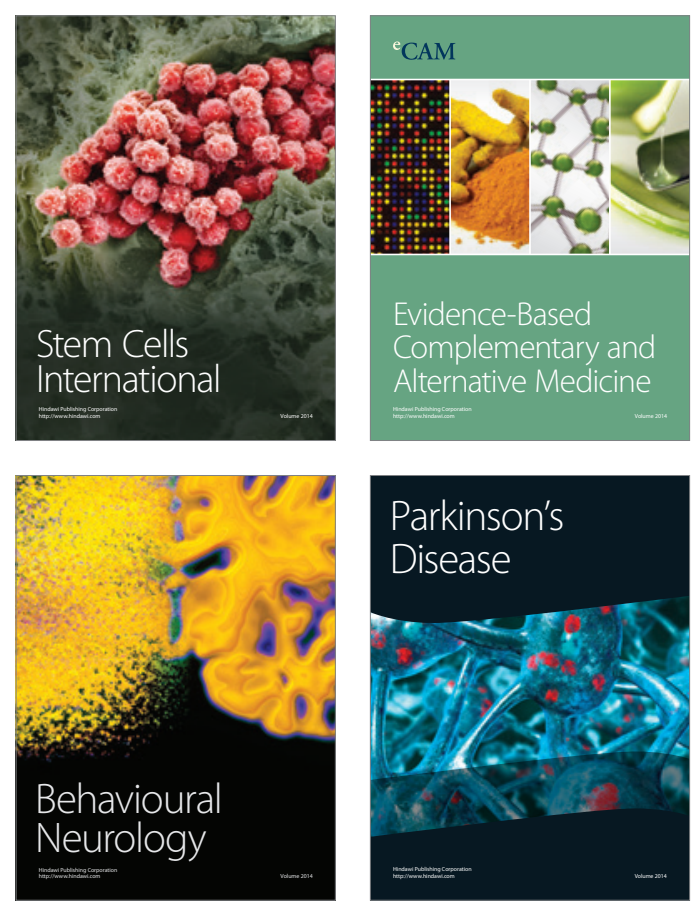

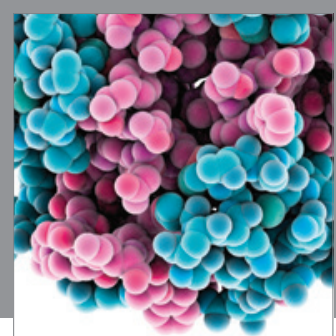

Journal of
Diabetes Research

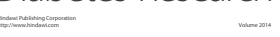

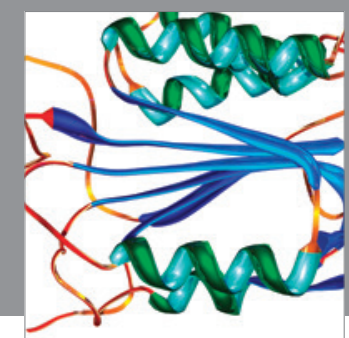

Disease Markers
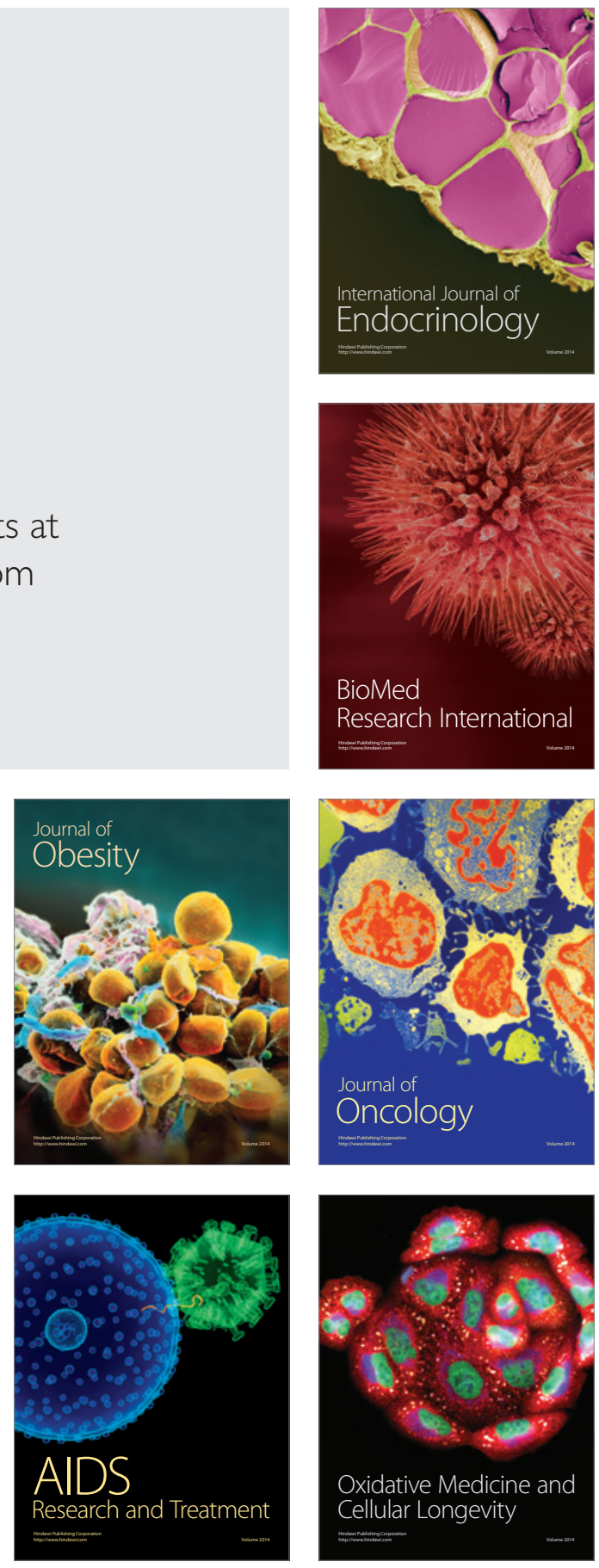